\title{
Green Renewable energy - Risk need to be tackled in going green for air transportation
}

\author{
Hazariah Mohd Noh Gustavo Alonso Rodriges \\ Nor Aida Abdul Rahman \\ aUniversiti Kuala Lumpur, Malaysian Institute of Aviation Technology (UniKL MIAT), Selangor \\ Malaysia \\ ${ }^{\text {b} E s c u e l a ~ T e c n i c a ~ S u p e r i o r ~ d e ~ l a ~ I n g e n i e r o s ~ A e r o n a u t i c o s, ~ U P M, ~ P l a z a ~ d e ~ C a r d e n a l ~ C i s n e r o s ~} 3$, \\ 28040, Madrid, Spain \\ hazariah@unikl.edu.my,gustavo.alonso@upm.es,noraida@unikl.edu.my
}

Keywords: Air Transportation, Bio jet fuel risk, Technical Risk, Quality Risk

\begin{abstract}
This paper will discuss on issues of using alternative fuel (bio jet fuel) for $50 \%$ mixing or replacing current Jet A/ Jet A-1 fuel in relationship towards aircraft fuel systems. Two key issues aviation biofuel; Technical Risk and Quality Risk will be evaluated. Technical risk, such as storage stability for biological growth, thermal stability in relation to fuel system components coking, the outcomes from combustion properties and material compatibility to the engine system and discussions on the level of the trace of contamination like metals or micronutrients. In quality risk, the issues need to be measured: the inconsistency of the products such as the source dependencies, robustness control and fragmented enterprise. These two issues need to be measured in order to create a clear pathway for Air Transport in sustainable manner, where further research towards reliability and sustainability for future aircraft performance and maintenance can be correlated.
\end{abstract}

\section{Introduction}

Aviation contributions to climate change as (IPCC 1996) represented 3.5\% of the total anthropogenic RF in the year of 1992. According to [1] it will be projected to increase to $5 \%$ for a mid-range emission scenario by 2050. As the discussion on overall transportation sector, it is a crucial and growing distribution of world energy use and emissions of GHG's. [2] In 2000, top three energy use can be seen in Table 1. (IEA, 2006.)[3]

Table 1: World transport, energy use in 2000 according to mode of transport.

\begin{tabular}{lll}
\hline Mode & Energy use (EJ) & Share \% \\
\hline Light duty vehicles & 34.2 & 44.5 \\
Heavy Freight trucks & 12.48 & 16.2 \\
Air & 8.95 & 11.6 \\
\hline
\end{tabular}

This paper is a study of risk into the current energy being used in the aircraft and the proposal of a new energy management system that leads to less emission, and cleaner combustion. The world's energy, mostly provided by fossil fuels is continuously rising, especially in the developing countries. [4] The security concerns of sources ending in the near future, the continuously increasing of the fuel price, and the more critical now is energy sustainability challenges towards the environment. [5]

\section{Methodology- the indicator system of sustainability \\ Bio jet fuel Key Issues in Aviation}

In developing sustainable development, there will be challenges that demand to be tackled. Two issues in the use of biojet fuel towards aviation can be categories as technical risks and quality risk, where defining green energy can be emerge towards sustainability.

\section{Technical Risks}

Storage stability - water and biological growth. Aircraft containing no water is impossible. This saturation level of a normal jet fuel is in part per millions (ppm) that's equivalence 
of temperature in degrees Fahrenheit, $50 \mathrm{~F}$ [10c] which may contain 50ppm of dissolved water.[6] Results from the flight test on Air New Zealand 32.2 ppm, 34.0p.m.- Continental Airlines and 19.0 p.m.- Japan Airlines, when using biomass from Camelina, Jatropha and Algae. [7]. When the temperature is super cooled, this water droplet and fuel combine to form a frozen substance often call Gael 'or icing.[8] In the current fuel usage, additives need to be subordinate in order for the anti-icing and anti microbiocidal agents.

Thermal stability - fuel system component coking. The main characteristic of gas turbine engine is Thermal Efficiency. It is the ratio of the fuel energy input to Turbine Inlet Temperature (TIT), Compression ratio, and component efficiencies (compressor and turbine). [9] Thermal stability can be depicted as the ability of the fuel to maintain stable characteristics in spite of increased temperature, where test conducted by JFOT (ASTM D324) monitored breakpoint at which the fuels meet the specification requirements. [10] In the (IATA Alternative fuels, 2009) minimum requirement for its stability of $260^{\circ} \mathrm{C}$, the alternative biomass giving the highest result with the value of $300{ }^{\circ} \mathrm{C}$. Test proven with specific analysis by following the ASTM D3241 at the same time the aircraft engines \& components need to be secured for future fuels in the contents of tolerant of future fuels for (low lubricity, low aromatic. [11] [12]

Combustion properties. Aircraft engines produce emissions that are similar to other emission produced by fossil fuel combustion.

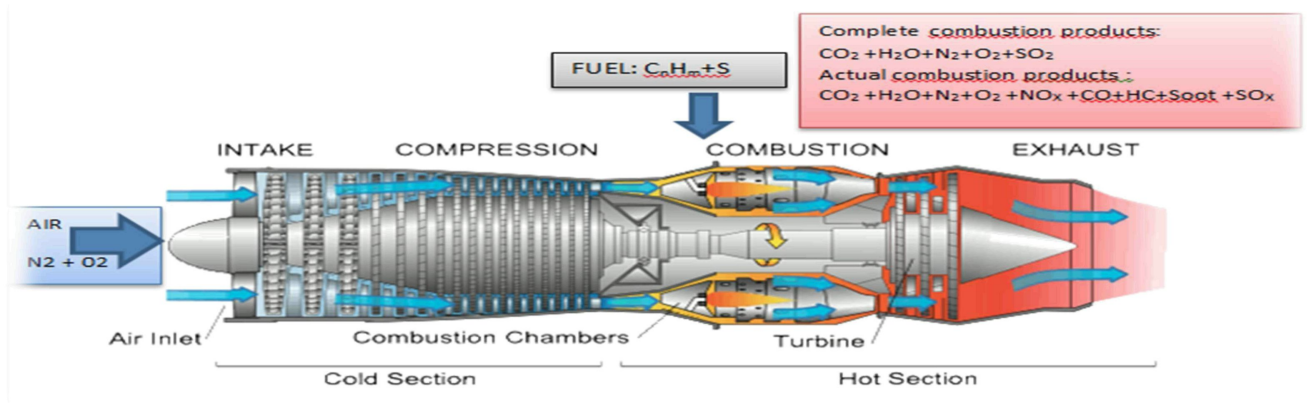

Figure 1: Turbine engine complete combustion products.

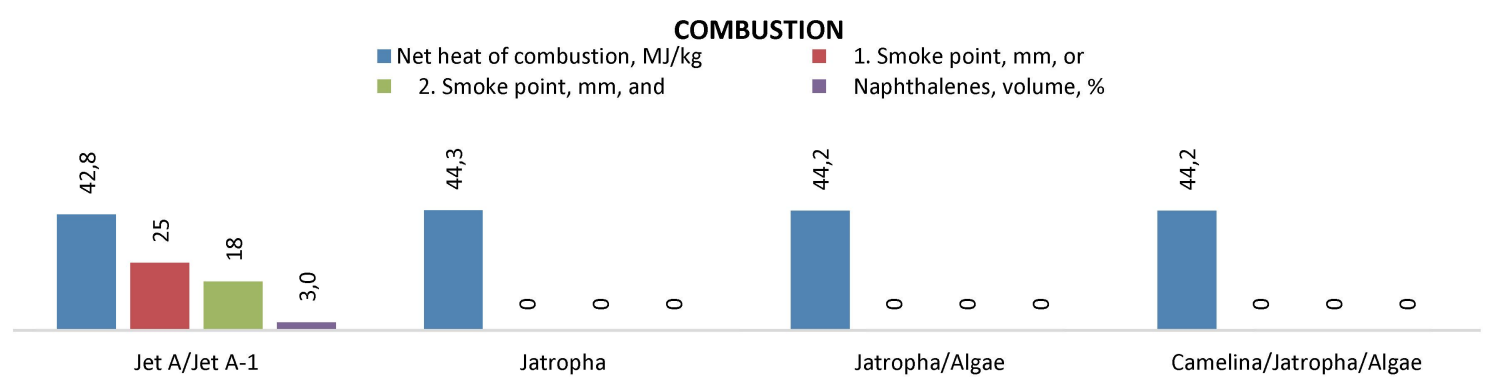

Figure 2: Combustion properties in biofuel test-BioSPK

The exhaust gas is roughly about $70 \%$ of $\mathrm{CO}_{2}$. A little less than $30 \%$ non- $\mathrm{CO}_{2}$ emissions include water vapor $\left(\mathrm{H}_{2} \mathrm{O}\right)$, and less than $1 \%$ of each nitrogen oxides (NOx), sulfur oxides (SOx), hydrocarbons (HC), and black carbon (or soot) particles, as in fig. 1. Comparable to fig. 2, with three differences of biojet fuel, clear results can be obtained.

Material compatibility - fuel system and hot section. Modification in fuel or fuel additives needs to be parallel towards the compatibility with the material used in the aircraft fuel system and engine hot section. Other materials used extensively are elastomeric seals and plastic seal backups. The most widely used elastomer seal. In the variety of properties for the biofuel, testing had proven the current biofuel uses in the flight, giving no harm and positive result of the components, seals and bearing. [13]

Trace contamination (metals, micronutrients). In Bio SPK (2009) report, the sample was examined for low level of impurities which can lead to reducing in aircraft engine fuel performance. There's no any traceable amount of impurities occurs for present of sulfur, nitrogen and oxygen compounds to the addition of 21 metals. [7] Fig.3. 


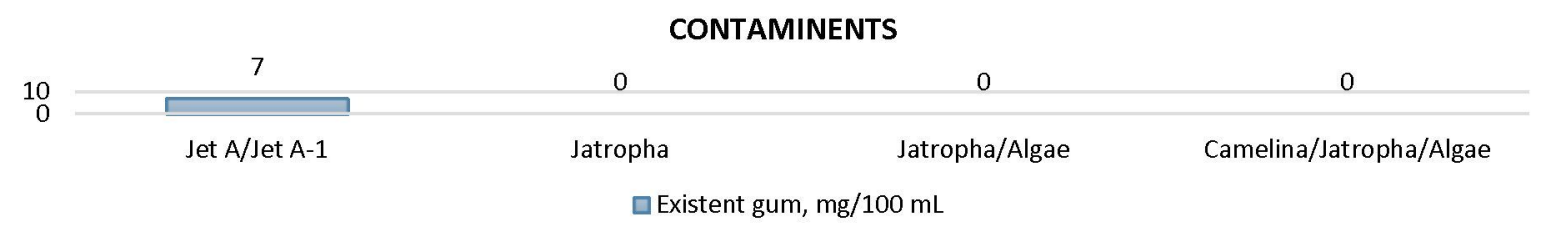

Figure 3: Contaminants properties in biofuel test-BioSPK

\section{Quality Risks}

Inconsistent product -biomass source dependent. The inconsistency or variability is the biggest enemy to the quality. Thus, in Snee and Hoerl (2003) the quality is at risk, if control over inconsistency or variability are hard to achieve. The study of algae as one of the biofuel that said to be one miracle solution for the replacement of today's petroleum product. However, further research need to enhance the best of what Algae can make out to the aviation industries. [14] Another example of inconsistent biofuel product that has been influenced by the lack of resources is Jatropha. In order to produce Jatropha, more modernized agricultural management, better soil and a lot of water. In recent biofuel schedule flight test BurnFAIR 2012, Lufthansa agreed that this source dependent bio jet fuel can be managed in future, proven by the five times flight per day from Hamburg to Frankfurt. [15]

Shortage of robust control. Quality means having the desired functionalities. Robust control can be simply as wider and bigger area of control; especially in the case of biofuel. [16] There are many components involved to manufacture biofuel. Raw material or feedstock is one of the main things needed to produce any type of biofuel. There are few type feedstock that being said have a big potential to be commercialized; Jatropha curcas, Camelina Sativa, Salicornia Bigelovii and last but not least Algae. [17] Making sure of the viability of the land for the production of feedstock are the way to take control over this problem. All of these 'uncontrolled' or ' under controlled are contributing to deficiency of supply of biomass to produce biofuel lead to deficiency of supply of production of biofuel. [18]

Fragmented industry. Bio jet fuel for aviation industries can be grouped as fragmented industry, where it's an industry that have many participants, but no even a single company that manage to possess a large market share. This is not a complete indicator shows the industry is not profitable or do not have a progress, growth, but it is more to the positive effect of low barrier for newcomer and higher opportunity for quicker profit yield. [19] Biofuel manufacturer struggling in measuring the application of the economies of scale to decrease the unit cost of product through mass production. Biofuel industry also following the same business activity as the biofuel producers face a few main limitations towards mass production, like limited know-how and confirmed data, lack of land and resources, also competition for other development like food production and nonenergy uses. [20]

\section{Discussion}

Aviation industries and safety cannot be separated, due to the standard and benchmark of quality of jet fuel that must be complied and oblige by the aviation industries, such as risks mentioned and discuss above. The researcher, practitioner and the policy maker, need to ensure these characteristics to be proper measure and handling in guarantee the application of biojet fuel for aviation specification is successful.

\section{Conclusions and future study.}

In tackling down the key issues of biojet fuel for aviation, it is necessary that all aspects to be covered. This includes, but is not limited to, application, operation and maintenance perspective. The effects on the relationship of each may be different and can lead to future prediction in preventive maintenance and towards the most crucial thing 'which is cost'. As each relationship becomes more prevalent in the transition, sustainability needs to be established in examining the impact of all. 


\section{REFERENCES}

[1] D. S. Lee, D. W. Fahey, P. M. Forster, P. J. Newton, R. C. N. Wit, L. L. Lim, B. Owen, and R. Sausen, "Aviation and global climate change in the 21st century," Atmos. Environ., vol. 43, no. 22-23, pp. 3520-3537, Jul. 2009.

[2] K. Ribeiro, S. Kobayashi, M. Beuthe, J. Gasca, D. Greene, D. S. Lee, "Transport and its infrastructure," Clim. Chang. 2007 Mitigation.

[3] IEA, "World Energy Outlook, International Energy Agency 2006,"

[4] I. E. Agency, "World Energy Outlook." [Online]. Available: [Accessed: 03-May-2014]

[5] IATA, "IATA 2013 Report on Alternative Fuels 8th edition Dec 2013," 2013. [Online]. [Accessed: 29-Apr-2014].

[6] "IATA Annual Report 2010." [Online]. Available: [Accessed: 03-May-2014].

[7] T. R. James D. Kinder, "Evaluation of Bio-Derived Synthetic Paraff. Kerosenes 2009,"

[8] Roll Royce, Rolls-Royce-JET-ENGINE.pdf, Fifth edit. 1996.

[9] Inc. Jeppesen Sanderson, A\&P Technician Powerplant Textbook.

[10] S. Jain and M. P. Sharma, "Thermal stability of biodiesel and its blends: A review," Renew. Sustain. Energy Rev., vol. 15, no. 1, pp. 438-448, Jan. 2011

[11] S. Dufferwiel, "Alternative Aviation Fuels Aromatics \& Thermal Stability," May, 2011.

[12] Thong D. Honga, e, T. H. Soerawidjajab, I. K. Reksowardojoa, O. Fujitac, Z. Dunianid, and M. X. Phame, "Production process - Experimental and theoretical evaluation of their blends with fossil kerosene," Chem. Eng. Process. Process Intensif., pp. 124-130.

[13] B.M. Jenkins, L.L. Baxter and T. R. Miles, "Combust. properties of Biomass," 1998.

[14] S. Nair and H. Paulose, "Emergence of green business models: The case of algae biofuel for aviation," Energy Policy, vol. 65, pp. 175-184, Feb. 2014.

[15] MTU Aero Engine, Technical Memorandum Project FAIR, vol. M 12 TEA-0. 2012.

[16] A. M. Omer, "Energy, environment and sustainable development," Renew. Sustain. Energy Rev., vol. 12, no. 9, pp. 2265-2300, Dec. 2008.

[17] Hazariah Mohd Noh et al., "Short-Term and Long-Term Feedstock Bio Jet Fuel " Appl. Mech. Mater., pp. 572- 577, 2012.

[18] W. W. M. Van Der Laak, R. P. J. M. Raven, and G. P. J. Verbong, "Strategic niche management for biofuels : Analysing past experiments for developing new biofuel policies," vol. 35 , pp. 3213-3225, 2007.

[19] I. Awudu and J. Zhang, "Uncertainties and sustainability concepts in biofuel supply chain management: A review", Renew. Sustain. Energy Rev.,vol.16, no. 2, pp.1359-1368,2012.

[20] W. K. Jaeger and T. M. Egelkraut, "Biofuel economics in a setting of multiple objectives and unintended consequences," Renew. Sustain. Energy Rev., vol. 15, no. 9, pp. 4320-4333, 2011. 